\title{
Procesos de subalternización de la población indígena en Argentina: los ranqueles en La Pampa, 1870-1970
}

por

\author{
Claudia Salomón Tarquini
}

CONICET-Instituto de Estudios Sociohistóricos-Universidad Nacional de La Pampa

A partir de las campañas militares de 1878-1885, conocidas en Argentina como "Conquista del Desierto", las poblaciones indigenas ensayaron distintas estrategias para enfrentar las condiciones adversas y las políticas que pretendian su subalternización e invisibilización. Este trabajo explora las particularidades del proceso protagonizado por el grupo étnico ranquel en La Pampa (primero Territorio Nacional y luego provincia a partir de 1952) desde los últimos años de su autonomía y hasta la década de 1970. El estudio se basa en una triangulación de fuentes de diverso tipo que, reduciendo la escala de análisis, toma como ejemplo la trayectoria de las agrupaciones ligadas al cacique Ramón Cabral, El Platero.

Palabras Clave: Pampa; poblaciones indigenas; estudios subalternos; estrategias de resistencia

\section{INTRODUCCIÓN}

Durante la última década, se han experimentado avances de importancia en los estudios relativos a los procesos de invisibilización y asimilación de las poblaciones indígenas en Argentina en el marco de construcción de los estados nacionales modernos y, a su vez, en la indagación en torno a las estrategias elaboradas por estos actores en distintos contextos ${ }^{1}$. Desde nuestra

1 Para un estudio de tipo general véase Mases 2002, y sobre los procesos de invisibilización de la población indígena, Quijada 1998 y 2003. Respecto de la discusión en el ámbito del Congreso acerca de la situación de los indígenas, Lenton 1997; las políticas oficiales en Chile hacia los indígenas en Boccara y Seguel-Boccara 1999. Pinto Rodríguez 2001; para un análisis de la subalternización en Neuquén, Sánchez 2003. En Río Negro, Argeri 2005. En Nordpatagonia, Briones y Delrio 2002, Delrio 2002 y 2005 y Nicoletti 2008; en provincia de Buenos 
perspectiva, analizar las modalidades adquiridas por la subalternización requiere conocer las cantidades de población existentes en distintos espacios, sus ciclos migratorios y las redes de relaciones familiares que podrían haber operado para amortiguar el impacto de políticas sumamente hostiles que pretendían la completa desarticulación de los grupos tribales. En ese sentido, daremos cuenta aquí no sólo de las condiciones de subalternización y asimilación, sino de las estrategias de los actores indígenas en Argentina, particularmente en el Territorio Nacional de La Pampa — actual Provincia de La Pampa ${ }^{2}$ y con respecto al grupo étnico conocido como ranquel $^{3}$ entre fines del siglo XIX y mediados del XX. Cuando se requieran ejemplos, traeremos a colación principalmente la trayectoria familiar de los descendientes del cacique Ramón Cabral, El Platero ${ }^{4}$, cuya parcialidad perdió autonomía en tiempos anteriores a las campañas militares de 1878-1879, pues se trata de uno de los grupos respecto de los cuales se cuenta con mayor documentación disponible.

El concepto de subalternidad, ampliamente discutido en el propio campo de los estudios subalternos (Rodríguez 1998), permite asimismo el abordaje de procesos históricos protagonizados por sectores ${ }^{5}$, como los pueblos origina-

Aires, Hernández 1993. La situación del Chaco, donde se observan similitudes con pampa y norte de Patagonia en el mismo periodo, Lagos 1998, y para el área de la actual provincia de La Pampa, Prins 1987. Villar 1993. Depetris y Cazenave 1998. Depetris \& Vigne 2000. Lluch 2002. Depetris 2003.

2 De aquí en adelante, las referencias geográficas que se mencionan en este trabajo podrán visualizarse en la Figura 1.

3 Las primeras noticias documentales de los ranqueles, rankeles (o rankülche como se autodenominan en la actualidad) los ubican desde la década de 1770 en el área que se denominaba Mamüll Mapu (País del Monte), es decir, el «... monte pampeano — dominio del caldén (Prosopis caldenia) y del algarrobo (Prosopis alba) — que se extiende bajo la forma de una cuña orientada del Nordoeste al Sudeste, sobre todo al oriente del sistema fluvial actualmente denominado Atuel-Salado-Chadileuvú-Curaco - tributario del Río Colorado - y va desapareciendo gradualmente al encontrarse con la llanura herbácea del Este, es decir, la pampa bonaerense». Villar y Jiménez 2003: 17.

4 Apodado de esta forma por su habilidad en la orfebrería de la plata, una artesanía típicamente masculina en los grupos del centro sur de Chile y de la región pampeana.

5 Ileana Rodríguez participó de la reunión de intelectuales conocida como Grupo Latinoamericano de Estudios Subalternos (GLES), cuyo Manifiesto Inaugural sostenía que «... El subalterno no es una sola cosa. Se trata, insistimos, de un sujeto mutante y migrante. Aun si concordamos básicamente con el concepto general del subalterno como masa de la población trabajadora y de los estratos intermedios, no podemos excluir a los sujetos "improductivos", a riesgo de repetir el error del marxismo clásico respecto al modo en que se constituye la subjetividad social. Necesitamos acceder al vasto y siempre cambiante espectro de las masas: campesinos, proletarios, sector formal e informal, subempleados, vendedores ambulantes, gentes al 
rios, largamente ignorados por las historiografías nacionales, sin limitar el análisis de su incorporación al estado nación únicamente a las condiciones de subordinación económica.

En este artículo, consideramos a la subalternización como el proceso mediante el cual ciertas políticas promovidas por el estado-nación argentino tendieron a lograr que los grupos indígenas pasaran a convertirse en sectores subordinados. Este proceso requirió no sólo su previa derrota militar, sino también una serie de medidas orientadas a deslegitimar su control territorial y - mediante discursos ampliamente difundidos en la sociedad hegemónica- a decretar su «inviabilidad» como sociedad al interior de la nación argentina. Si bien fueron discutidas la posibilidad de asimilación, los rasgos que la distinguían, y la calidad y cantidad de medios afectados al objetivo de llevarla a cabo, todas las soluciones ensayadas partieron de la irreversibilidad de su inclusión en condiciones de subordinación, anclada en una noción de aboriginalidad - elaborada ya a principios del siglo XIX — que confinaba a los indígenas a un pasado remoto y superado, y los condenaba a una segura extinción (Briones 2004).

Las relocalizaciones masivas que conllevaron la separación de familias entre sí y la anulación de sus liderazgos fueron las principales prácticas que, en los planes de las elites dirigentes, asegurarían - aunque no su desaparición física- sí la existencia misma de los sujetos de tales políticas como grupos sociales. No obstante, es notable ver cómo estos últimos buscaron revertir los efectos adversos que recaían sobre ellos, reconstruyendo vínculos perdidos y estableciendo otros nuevos con sus paisanos (población nativa del mismo lugar de origen), a lo largo de las décadas subsiguientes a la debacle. Esas iniciativas subalternas de contestación, silenciosas y necesariamente fragmentadas (Gramsci 1998: 361), pueden ser rastreadas en los archivos a través - por ejemplo - del análisis de las redes sociales tejidas en estas circunstancias y su anclaje en relaciones previas establecidas desde antes de la pérdida de autonomía.

margen de la economía del dinero, lumpen y ex-lumpen de todo tipo, niños, desamparados, etc.» (GLES 1998: 8). Varias han sido las discusiones en torno a los alcances de la subalternidad como herramienta conceptual para dar cuenta no sólo de procesos sociales que el marxismo ortodoxo y las historiografías nacionales habían descuidado, sino también de las propias situaciones de desigualdad entre las academias de países dominantes y los colonizados (como los de América Latina y del sur asiático). Por razones de espacio, no podemos detenernos aquí en estos debates sobre subalternidad y poscolonialismo, que pueden seguirse en los aportes de Mallon, 1995. Moraña, 1998. Chakrabarty, 2000. Beverley, 2001. Rodríguez, 2001. Guha, 2002. Mezzadra, 2008. Moraña, Dussel y Jáuregui, 2008, entre otros. 
FIGURA 1. MAPA CON LAS PRINCIPALES REFERENCIAS GEOGRÁFICAS

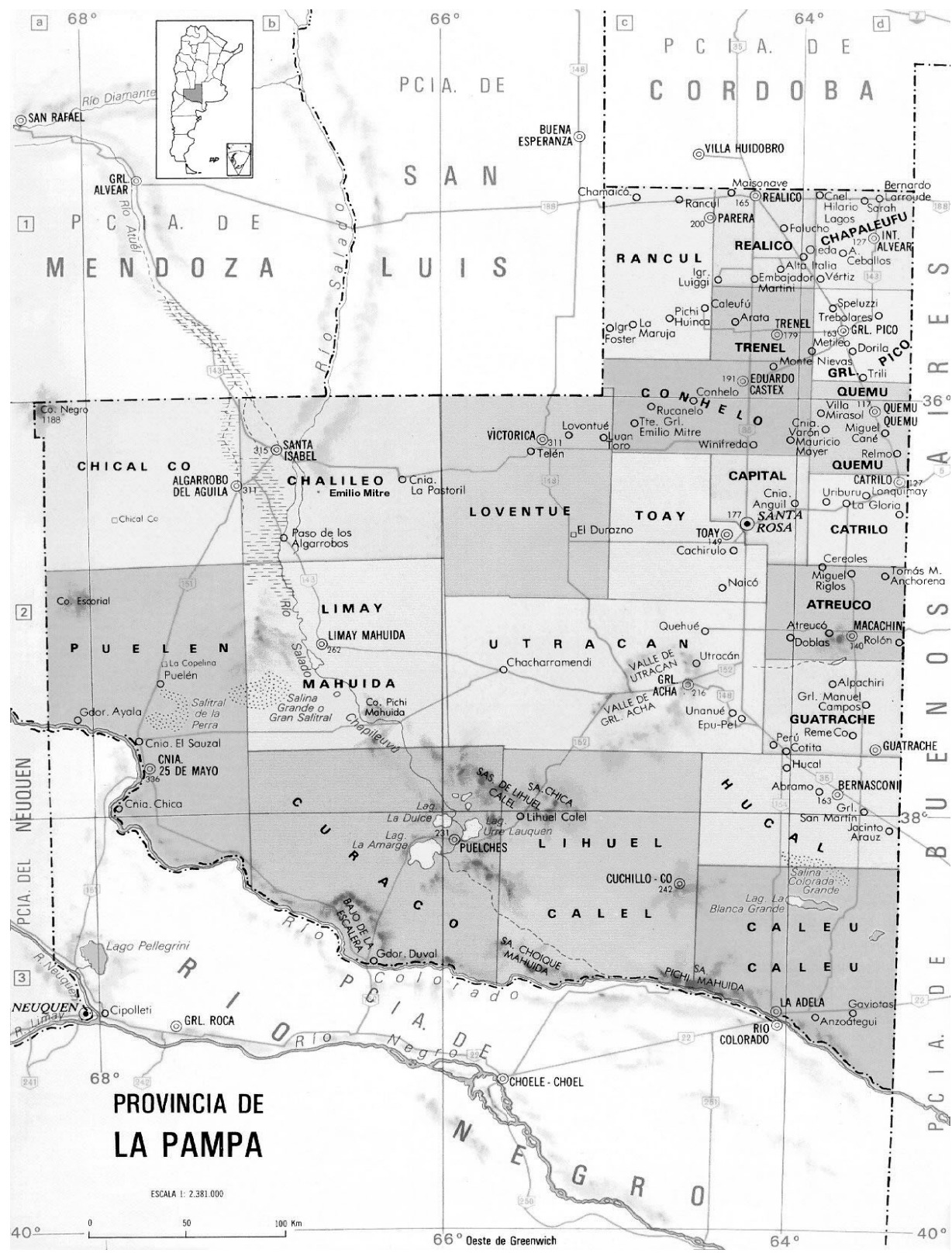

Fuente: www.mapasdeargentina.com.ar 
Por ello, en cuanto a las fuentes, metodología y técnicas utilizadas en este tipo de análisis, cabe sostener que para actores subalternos, cuyos registros son apenas indiciarios, el espectro de fuentes es necesariamente amplio: aquí se realiza una triangulación de los datos obtenidos en el diario de Lucio V. Mansilla $^{6}$, los registros de los sacerdotes franciscanos y salesianos, registros civiles y electorales, informes de inspección de tierras, informes de viajeros, y testimonios orales. Hemos reducido la escala de análisis pues el enfoque microanalítico nos permite observar dinámicas que pasan desapercibidas en un contexto más amplio como el de la totalidad de la población pampeana. Los datos nominativos ${ }^{7}$ fueron procesados con los programas Access (bases de datos) y Genopro (genealogías) para la reconstrucción de trayectorias.

\section{LOS ÚLTIMOS AÑOS DE AUTONOMÍA (1850-1878)}

Para comprender el proceso mediante el cual los ranqueles pasaron a convertirse en sectores subalternos, es necesario que repasemos, en primer lugar, los momentos previos a las campañas militares — conocidas como «Conquista del Desierto»—, particularmente virulentas para aquéllos en su primera etapa, es decir, durante los años 1878 y 1879.

Hacia mediados del siglo XIX, tres grupos se destacaban en la región de pampa y nordpatagonia en términos de capacidad bélica e importancia demo-

6 «De personalidad multifacética (1831-1913) se destacó como militar y escritor, ocupaciones que alternó con largos viajes, compromisos políticos, intensa labor periodística y una activa vida mundana. "Enfant terrible" de su época y de su sociedad, fue un observador escéptico, risueño y a menudo mordaz. Murió en Europa desempeñando tareas diplomáticas». Mandrini, 1984. En 1870, mientras se encontraba a cargo de la comandancia militar de la frontera de Río Cuarto, realizó un viaje a los principales asentamientos ranqueles con motivo de la firma de un tratado de paz, y escribió los relatos conocidos como Una excursión a los indios ranqueles, un «clásico» del que existen varias ediciones en Argentina. En este trabajo, las citas corresponden a Mansilla 1980.

7 Registros de nacimiento, matrimonio y defunción en la Dirección de Registro Civil de la Provincia de La Pampa, y fichas individuales (conocidas como formularios F5) en el archivo de la Secretaría Electoral del Juzgado Federal de Santa Rosa, La Pampa (en adelante JFSR). Estas fichas — que se utilizan hasta la actualidad como insumo para la elaboración de los padrones electorales - tienen la particularidad de incluir los datos filiatorios y todos los cambios de domicilio y ocupación que registra una persona a lo largo de su vida desde los 16 años. Muchos de los datos obtenidos para las primeras generaciones se ajustaron en función del contenido de doce testimonios orales recibidos a personas apellidadas Cabral, en un relevamiento realizado por personal del Archivo Histórico Provincial de La Pampa (en adelante AHP) en 1997, con la colaboración de familiares (por lo general nietos o sobrinos) de los informantes, cuyas grabaciones y transcripciones se encuentran reservadas en ese repositorio. 
gráfica: los ranqueles (cuyos líderes más prominentes entre 1830 y 1878 fueron sucesivamente Yanquetruz, Pichuiñ, Painé, Panghitruz-Guor -Mariano Rosas-, Epugner Rosas, Ramón Cabral y Baigorrita), los salineros (encabezados, aproximadamente dentro del mismo periodo, por los caciques Calfucurá y Namuncurá) y el grupo de Pincén.

Estas jefaturas indígenas se apoyaron en una serie de agrupamientos y redes de alianzas fluctuantes, en la que líderes como Mariano Rosas o Calfucurá no siempre lograban concertarse con otros grupos, ni tenían plenamente garantizada la lealtad permanente de sus propios konas $^{8}$. En esas redes no sólo tenían peso los vínculos más o menos estables que se procuraran establecer (a través de los matrimonios por ejemplo), sino también las lecturas del contexto geopolítico que cada líder podía hacer en base a los abundantes datos que recababan como nodos centralizadores de información ${ }^{9}$, y las políticas estatales que mediante diversos dispositivos de poder pretendieron $-\mathrm{y}$ en cierta medida lograron - intervenir sobre la conformación de alianzas políticas indígenas ${ }^{10}$.

A principios de la década de 1870, tres circunstancias contribuirían a minar la capacidad bélica de los indígenas en general y de los ranqueles en particular: la desarticulación de las montoneras provinciales (con las que éstos tenían firmes alianzas), la finalización de la guerra contra el Paraguay (1865-1870) y el avance de la frontera sur de Córdoba hasta el Río Quinto. Así, en 1872, a la novedosa utilización del telégrafo para mejorar la capacidad de comunicación de las guarniciones militares y al tendido ferroviario que había llegado hasta Río Cuarto, se le sumaron algunas campañas sobre las tolderías ranqueles en 1871 y 1872 - que demostraron la asimetría militar existente-, la designación de Julio Argentino Roca como jefe militar a la frontera de Río Cuarto, con planes más ofensivos, y la llegada de las tropas que habían combatido en el Paraguay, con una clara conciencia de subordinación a la autoridad nacional ${ }^{11}$. De aquí en más, la nueva situación planteada y las estrategias del gobierno nacional no harían sino fomentar constantes divisiones y diferencias entre los grupos indígenas y promoverían la reducción de algunos contingentes ranqueles, como veremos más adelante.

${ }^{8}$ En mapudungun, la lengua hablada en los siglos XVIII y XIX por las poblaciones indígenas de la zona, el término kona hacía referencia a los hombres adultos capacitados para tomar las armas.

9 Bechis, 1999: 17.

10 Sobre el papel del estado y las políticas de alianzas de los ranqueles véase Pérez Zavala 2007 y de los salineros, De Jong 2007.

11 Pérez Zavala, 2007: 75-77. 
Cuando en su famosa «excursión» de 1870, el coronel Lucio V. Mansilla recorría los asentamientos de Mariano Rosas, Baigorrita y Ramón Cabral, se sorprendió por la prosperidad que encontró en las tolderías de este último, ubicadas en Carrilobo (ó Carriloo), y señalaba: «La familia del Cacique consta de cinco concubinas, de distintas edades, una cristiana y cuatro indias, de siete hijos varones y de tres hijas mujeres, dos de ellas púberas ya. /.../ No hay indio ranquel más rico que Ramón, como que es estanciero, labrador y platero. Su familia gasta lujo. Ostentaban hermosos prendedores de pecho, zarcillos, pulseras y collares, todo de plata maciza y pura, hecho a martillo y cincelado por Ramón; mantas, fajas y pilquenes de ricos tejidos pampas» ${ }^{12}$.

Sin embargo, esa pujanza tenía lugar en un contexto de creciente debilidad que desembocaría en una serie de opciones de difícil resolución: resistir los ataques militares cada vez más frecuentes, negociar con las autoridades nacionales, reducirse en calidad de indios amigos, o bien replegarse a zonas que los ejércitos nacionales aún no controlaban. Estas posibilidades fueron utilizadas alternativamente por los distintos grupos, marcando puntos de irreversibilidad en las relaciones. Un incierto futuro, la gravosa incidencia de enfermedades mortales y de una progresiva escasez de recursos impregnarían a esas decisiones de perdurables efectos que se proyectarían más tarde sobre las configuraciones de los sobrevivientes a las campañas militares iniciadas en 1878 y finalizadas en Patagonia hacia 1885. Los tratados de paz con los ranqueles, y en particular el de 1872, al tiempo que reflejaban las crecientes condiciones de asimetría entre el estado nacional y los contingentes indígenas, generaban disputas al interior de éstos o profundizaban las rivalidades existentes, debilitando aún más las capacidades de negociación (Tamagnini \& Pérez Zavala 2002).

El grupo de Ramón Cabral fue uno de los principales afectados por el avance de la frontera sur de Córdoba: la viruela, los constantes ataques militares que tenían como único fin quitarle personas y ganado y el fantasma del hambre comenzaron a mermar sus fuerzas. En esas condiciones se produjeron tres desmembramientos importantes entre su gente: el primero de ellos tuvo lugar en 1872, con la presentación ante la comandancia militar de las familias - catorce en total - del capitanejo Simón Martín, el lenguaraz Francisco Mora y Martín López; el segundo, a partir de mayo de 1874, momento en que se presentaron en Fuerte Sarmiento el capitanejo Bustos (con 6 indios y siete chinas), Juan Villarreal (con 64 personas) y Santos Morales (con 14) y -en agosto del mismo año - Linconao Cabral — hermano del cacique Ramón Ca-

12 Mansilla, 1980: II-174. 
bral. Finalmente - y aunque se había procurado convencerlo de instalarse entre los criollos desde 1874 - no fue sino hasta 1877 en que el propio Platero «aceptó» resignar su autonomía ${ }^{13}$.

Una vez instalados en los puestos militares fronterizos, y pese a las promesas en contrario, los racionamientos comenzaron a demorarse, las semillas e instrumentos de labranza no llegaron (o lo hicieron de forma muy esporádica) y se les presionó cada vez más hasta exigírseles prestar servicio militar en las campañas de 1878-1879 contra quienes habían quedado en Tierra Adentro' ${ }^{14}$.

Estas campañas destruyeron la existencia autónoma de las poblaciones indígenas al norte del río Colorado y fueron seguidas por la desarticulación de las formas de vida y organización de los sobrevivientes, basada en dos políticas claramente complementarias. Por un lado, se implementó la dispersión de familias, confinando a los varones adultos en prisión (por ejemplo, la isla Martín García, cercana a la costa uruguaya del Río de la Plata), o enviándolos a las distantes zafras azucarera, yerbatera y algodonera, o incorporándolos a la policía, ejército y marina, y afectando niños y mujeres al servicio doméstico en distintas ciudades del país. Por otro lado, autoridades de distinto tipo - en especial las de Territorios Nacionales - se negaron sistemáticamente a entregar tierras a quienes las solicitaran, lo cual implicaba no sólo un desconocimiento de los liderazgos previos sino también el impedimento para asentarse en forma concentrada en determinados lugares.

El cambio de su status en relación al estado-nación se completó con una progresiva subordinación que, según Delrio, se revela en la secuencia de las categorías sociales construidas a lo largo del proceso de incorporación: «indios amigos», «indios salvajes», «argentinos» o «rebeldes». La primera de ellas se aplicó en algunos casos, hacia mediados del siglo XIX, cuando el estado todavía no se encontraba en condiciones de encarar la disputa franca de los

13 «En 1877, el teniente Alberto Capdevilla fue destacado para arrebatar las caballadas al cacique Ramón. Las tropas del Fuerte Sarmiento salieron, pues, "en persecución de indios que habían robado la caballada del Regimiento 4." y el 18 de septiembre de 1877 , volvieron con 600 animales que habían pertenecido al cacique Ramón. Este se presentó de inmediato en la Comandancia para reclamarlos. Pero el coronel Racedo, quien había previsto el jaque de la maniobra, le impuso como condición de la entrega de los animales, que se viniera con su tribu a vivir en la zona denominado [sic] "Sarmiento Nuevo", prometiéndole paz, tierras y más animales. El cacique, después de reflexionar un rato, aceptó la propuesta, porque de lo contrario iba a exponerse a nuevos ataques y a la creciente pobreza. Tan sólo pidió una escolta de protección para venirse /.../ El coronel Racedo salió a su encuentro con unos 300 hombres y el cacique trajo más de 400 indios al Fuerte». Hux, 1991: 151.

14 Para más detalles sobre el proceso de reducción y las estrategias indígenas en ese contexto, ver Tamagnini \& Pérez Zavala, 2005 y 2007, y Salomón Tarquini, 2005. 
territorios nativos y se veía obligado a tratar paces; la segunda, en el contexto de las campañas militares de 1878-1885 para estigmatizar al enemigo, luego transformado en «argentinos» o «rebeldes», según se sometieran y aceptaran una localización espacial determinada, o persistieran en el camino de la guerra. En adelante, la resistencia a la invasión de sus territorios no sería entendida como un acto bélico, sino criminalizada, y en los años próximos, «lejos de producirse la homogeneización anunciada se cristalizó la construcción del permanente estado de desaparición de los grupos indígenas — o su «dilución» en la «civilización»/.../ Para los pueblos originarios la incorporación al estado-nación se caracterizó por medidas especiales que los separaban del conjunto de ciudadanos, aun de aquellos sin plenos derechos políticos») (Delrio 2002: 238-239). Entre estas medidas se encontraban el cambio de sus nombres por otros de origen hispano-criollo, la prohibición de hablar su lengua, la omisión de consignar su origen étnico en los recuentos censales (Otero 1998) y la criminalización de sus prácticas culturales.

\section{REORGANIZACIÓN DE LOS RANQUELES (1878-1900)}

En el marco de esas políticas, la instalación de grupos indígenas en el ahora Territorio Nacional de La Pampa ${ }^{15}$ en los últimos años del siglo XIX no respondió a sus propias motivaciones, sino a una serie de traslados forzados de contingentes militarizados pocos años antes de las campañas militares. Por otra parte, eludiendo las políticas oficiales de dispersión, un número de indígenas que resulta difícil estimar con precisión volvió a las tierras ocupadas antes de las campañas militares, desde las zonas seguras a las que se habían replegado durante la ofensiva o luego de fugarse tras su captura. Algunos de los destinos impuestos más importantes de esta etapa de traslados fueron Victorica, General Acha y La Blanca, aunque por esos años se verifica la presencia de población —en menor proporción - en otras localidades del Territorio, sobre el área occidental o centro-occidental ${ }^{16}$.

Durante esos desplazamientos, distintos grupos fueron reuniendo hacienda y recuperando los lazos familiares, mientras solicitaban tierras a los gobiernos

15 Tras la finalización de las campañas militares de 1878-1879, el espacio que actualmente comprende la provincia de La Pampa pasó a ser incorporado al estado nacional a partir de la sanción de la Ley n. ${ }^{\circ} 1532$ de 1884 . Sobre la creación de los Territorios Nacionales en Argentina y en particular el de La Pampa, véase Moroni, 2007.

16 En particular en localidades tales como Santa Rosa, Bernasconi, Jacinto Aráuz, Caleufú, Anguil General Manuel Campos, La Reforma, Luan Toro, Remecó y Rolón. 
nacionales y territorianos para asentarse. Sin embargo, la cantidad de ganado disponible — que aseguraba un mejor pasar-y el hecho de que algunos de ellos conservaran aún a principios de la década de 1890 sus grados militares no garantizaba, al menos en la percepción de los indígenas, la estabilidad del grupo, ni la posibilidad de evitar la desintegración de las familias. En 1891, por ejemplo, llamó la atención a uno de los sacerdotes franciscanos el temor que causaba a los indígenas la concentración de muchas familias. Pocos años antes, esa había sido la oportunidad en que los niños fueron arrebatados a sus padres. A su llegada a General Acha, los franciscanos le pidieron a Linconao Cabral que reuniera a la gente para bautizarla:

«éste pronto se puso a la obra, pero al proponérselo a sus hermanos, se encontró con alguna dificultad, que aquéllos temían que al bautizar a sus hijitos, los padrinos se los arrebataran, como les sucedió estando en Sarmiento, muchos años ha, habiendo bautizado a muchos indiecitos, los padrinos se apoderaron de ellos, arrancándolos de los brazos de sus padres, lo que fue una verdadera barbarie» [Pocos días más tarde], «... vimos venir al Mayor Linconao a la cabeza de la india$d a$, en número como de 150. Fue sumamente conmovedor ver a tantos pobres indios, los mismos que años no muy lejanos habian sido el terror de todos, ahora se presentaban humildes y sumisos, previa recomendación que no le quitaran los hijitos que tan entrañablemente querian...» ${ }^{17}$.

Los hombres de Ramón Cabral constituyeron el grueso del «Escuadrón Ranqueles», trasladado con motivo de la fundación de las primeras localidades del ahora Territorio Nacional de La Pampa Central (Victorica y General Acha, ambas fundadas en 1882). En ese año, llegó a Victorica el primer contingente, quedando parte de la población indígena en las reducciones de Sarmiento y Villa Mercedes (al sur de Córdoba y San Luis respectivamente) y en condiciones paupérrimas $^{18}$. En 1886, se les sumaron forzadamente otros ranqueles traídos

17 Crónica de la misión de los padres Herrera y Quaranta. General Acha, junio de 1891, citado en Depetris \& Cazenave, 1998: 38, mis resaltados.

18 Según el informe del sacerdote franciscano Quirico Porreca, prefecto de Misiones, al padre guardián del convento de Río Cuarto, en 1883 «el prefecto decide visitar las familias de indios situados en Victorica, pero no puede asistir por diversas causas, entonces decide recorrer los fuertes de Sarmiento y Villa Mercedes /.../ al llegar a aquella guarnición observa que los indios parecían cadáveres. Los chicos de éstos morían atacados por una doble enfermedad: el sarampión y la disentería, motivados por el hambre. Causado éste por la avaricia de los jefes, que insaciables para conseguir riquezas para hacerse opulentos y conservar sus vicios, quitan el pan de la boca a esos desgraciados indios /.../» (citado en Depetris \& Cazenave 1998: 39). Al parecer, a raíz de estos hechos, el gobierno «se ve obligado a levantar un sumario a los jefes por robos de sueldos, raciones y otras yerbas cometidas contra los indios reducidos». Depetris \& Cazenave, 1998: 39. 
desde Villa Mercedes y Sarmiento Nuevo hasta la localidad de General Acha ${ }^{19}$.

Asimismo, sobre fines de la década de 1890, una parte de este grupo fue llevado a La Blanca, un establecimiento rural en el Departamento Loventué y Conhello, diez kilómetros al este de Luan Toro. Luego de trabajosas gestiones de algunos líderes surgidos en esta etapa - entre los cuales se cuentan fundamentalmente Santos Morales (cuyo nombre indígena era Katrenao), Lucho Baigorrita (hermano del cacique Manuel Baigorrita, muerto en la campaña militar) y Francisco Ñankufil Calderón-, se obtuvieron tierras en las colonias pastoriles Emilio Mitre y Los Puelches (ambas fundadas en el año 1900), donde se congregaron varias familias del área ranquelina. Ramón Cabral no llegaría a ver a su gente reunida, pues había fallecido en mayo de 1890 .

Según el censo de 1895, Pichañá Antipán, mujer principal de El Platero, que por entonces tenía 70 años, se encontraba en el Departamento $7 .^{\circ}$ (área de Victorica), con su hijo Curunao Cabral, y sus nietos Luis, Antonino, Bonifacio y Catalina ${ }^{20}$. Cuando en adelante hagamos referencia a Antonino Cabral se tratará de este hijo de Curunao y por lo tanto, nieto de Ramón El Platero, que había nacido en La Blanca el 23 de diciembre de 1889. Su línea de descendencia ha podido reconstruirse con 34 de sus miembros más sus cónyuges.

\section{UNA AUTONOMÍA LIMITADA (1900-1950)}

Las tierras de las colonias Emilio Mitre y Los Puelches pronto se revelaron insuficientes: con una unidad mínima de productividad calculada actualmente en 5.000 has se les asignaron por entonces lotes de 625 has a cada familia, sin proveérseles medios de subsistencia adicionales. La ley número 1501 de Concesión de tierras públicas para ganadería (conocida como Ley Argentina del Hogar), a cuyo amparo se adjudicaron los lotes, prescribía la obligación de poblar (con ganados, cultivos y plantaciones) durante cinco años en forma ininterrumpida, levantar edificaciones e introducir hacienda por un capital aproximado de $\$ 250$, tras lo cual se entregarían los títulos de propiedad. Las

19 «A fines de febrero de 1886, el general Ayala abandona a Villa Mercedes, para dirigirse a la capital de La Pampa. Su viaje, a través de los arenales y desiertos puntanos y pampeanos, adquirió los contornos y características de un verdadero éxodo. La expedición estaba compuesta por treinta y seis carretas y crecido número de familias ranquelinas, reducidas hasta entonces en el pueblo fundado por fray Marcos Donati, en Villa Mercedes». Massa, 1967: I-320.

20 Según datos en Depetris, 2003: 71. 
fracciones asignadas eran además claramente inaptas para instalar en ellas una colonia pastoril. Desde el punto de vista fisiográfico, la zona central de los emplazamientos (que abarca el departamento Chalileo, oeste de los departamentos Loventué y Rancul y casi todo el departamento Limay Mahuida) se corresponde con un clima semiárido y su paisaje está compuesto por médanos, cordones arenosos, planicies arenosas y mesetas residuales.

En colonia Emilio Mitre, los funcionarios encargados de la medición y asignación de los lotes distinguieron «la tribu de Santos Morales» y «la tribu de Ramón Cabral $»^{21}$. En el caso del primero, se enumeraban sesenta y cinco cabezas de familia como solicitantes y cincuenta y cinco en el caso del segundo. En términos generales, a las familias Cabral y Carripilón se les asignaron lotes en el ángulo noroeste de la Colonia y a una parte del grupo de Santos Morales lotes en el centro-sur, aunque a éstos en forma dispersa dentro de la zona. Esa distribución inicial se vio modificada por progresivos reagrupamientos de las unidades domésticas según la disponibilidad de recursos —en particular el agua y las pasturas para haciendas - y vinculada claramente a relaciones de parentesco que, en diferentes grados, permitían por un lado la utilización en común de recursos naturales como las aguadas ${ }^{22}$, y por otro, evitaban la excesiva subdivisión transgeneracional de las fracciones. Los hijos de Ramón Cabral - Ramón Caleo y Curunao - se vincularán por matrimonio a las familias Canué, Lima y Carripilón en segunda o tercera generación. La contigüidad de los lotes ocupados da cuenta de una construcción social basada en la constitución de una red de parentesco. En el extremo noroeste de las tierras de la colonia (lotes 1 a 13 especialmente), esta relación se verifica especialmente ${ }^{23}$. Pese a las dificultades existentes para asegurar la subsistencia, es-

21 Ver duplicado de mensura del año 1899, Expediente número 518, Colonia Emilio Mitre, Dirección General de Catastro, provincia de La Pampa.

22 En aquellos casos que los inspectores de tierras registraban que el adjudicatario de un lote no daba de beber a su hacienda en su parcela, solían señalar que utilizaban las aguadas de parientes. También los registros de marca de hacienda se prestaban entre parientes: en 1909, por ejemplo, Ramón Caleo Cabral, uno de los hijos del cacique Ramón, facilitó su marca a Coche Cabral, Nicolás Cabral y Sandalio Fernández, ubicados respectivamente en los lotes cinco, seis y siete, contiguos entre sí. (Informe de Inspección de Tierras, 1909, Fondo Tierras, AHP).

23 He aquí algunos ejemplos, según datos obtenidos de los informes de Inspección de Tierras. Lote 1: adjudicado a Quintré Carripilón, casado con Cuché Comeñé, hija de Ramón Cabral, El Platero, y hermana de Curunao (lote 16 y de Ramón Caleo, lote 15); lote 8: adjudicado a Francisco Cabral en 1900, es ocupado al menos desde 1905 por Bonifacio Rosas, casado con Teresa Cabral, hija de El Platero (sobrina de Levinao); lote 9: adjudicado a Levinao Cabral, hermano de Ramón Cabral, es ocupado por éste hasta su muerte, tras la cual sigue ocupándolo su viuda, Tomasa ó Marcelina Miranda. Años después, Pablo Videla (de 26 años, hijo de Blas Videla) se encuentra ocupando el Lote 9 junto con Luisa Cabral, hija de Marcelina y Levinao; 
tas estrategias permitieron la permanencia en el lugar y, hacia 1913, los integrantes del principal núcleo - constituido por Ramón Caleo Cabral, Curunao Cabral, Coché Cabral y Blas Videla- lograron escriturar sus chacras.

En esos espacios trabajosamente construidos, tanto ellos como otros indígenas combinaron la cría de animales (especialmente lanares y chivos y algunas aves de corral como gallinas y pavos), la recolección de frutos (en particular del piquillín, chañar y algarrobo) y huevos de ñandú o de patos, y la caza de avestruces, vizcachas, piches, zorros, «y de cualquier carne que viniera», no sólo para consumo, sino también para la venta de cueros y plumas. Los chivos proveían carne de consumo propio, leche (para tomar, mezclar con maíz pisado, elaborar quesos y cuajar como alimento de gallinas y pavos) y podían ser vendidos a los «chivateros» que recorrían la zona. Las ovejas, además de carne, proporcionaban lana que, hilada y teñida con pigmentos de plantas de la zona, servía para tejer matras, ponchos, fajas y peleros comercializados con los «mercachifles» o vendedores ambulantes. Otra opción para obtener dinero fueron los trabajos asalariados por temporadas, de los cuales el más frecuente consistía en la formación de «comparsas» de esquiladores/as (compuestas por mujeres, hombres y niños mayores). Por ejemplo, Antonino Cabral, nieto de El Platero, fue capataz de una comparsa de esquiladores en la que participó su nieta, Perfecta Cabral, quien recuerda que se trasladaban hasta provincia de Buenos Aires a raíz de esa actividad ${ }^{24}$. Otras formas de trabajo asalariado estaban constituidas por las actividades como jornaleros en los establecimientos rurales, o como hacheros en los obrajes madereros del centro del territorio (de allí — suponemos - el traslado de estos trabajadores a la zona de Luan Toro y al departamento Conelo). A su vez, las mujeres se empleaban como lavanderas o niñeras en el servicio doméstico, abandonando los puestos en que habían habitado, ya sea en forma periódica o definitiva.

lote 10: adjudicado a Blas Videla, casado con Pichicaiún Cabral, hija de El Platero; lote 15: adjudicado a Ramón Caleo Cabral, hijo de Ramón Cabral El Platero, hermano de Teresa y Curunao, sobrino de Levinao; lote 16: adjudicado a Curunao Cabral, hijo de El Platero, hermano de Teresa y Ramón Caleo, sobrino de Levinao. Según datos de fichas individuales en Secretaría Electoral del Juzgado Federal de Santa Rosa, e las primeras décadas del siglo XX, Antonino Cabral, hijo de Curunao Cabral y nieto de Ramón El Platero, registrará como domicilio el lote 17, fracción D, Sección XVIII, al suroeste del Departamento Chalileo, junto con sus hijas Catalina, Desposaria, Luisa y Beneranda, todas nacidas en Emilio Mitre entre 1913 y 1924.

24 Testimonio en cinta 94, lado A, Fondo Rankel, AHP. 


\section{LA DISPERSIÓN DE LA POBLACIÓN INDÍGENA (1948-1970)}

Los ciclos de migración hacia las ciudades se iniciaron a mediados del siglo XX, a partir de experiencias previas de circulación motivadas por el desempeño de actividades laborales extraprediales que en ocasiones comenzaron siendo estacionales o temporales (para convertirse más tarde en permanentes). La esquila, la vendimia y otras tareas rurales (entre ellas la de alambrar y trasladar ganado), y el empleo doméstico se contaron entre las más habituales.

Estas migraciones comenzaron a hacerse cada vez más frecuentes a partir de mediados del siglo XX, cuando dos factores impulsaron el mayor éxodo de población desde el Oeste de La Pampa: por un lado, el incremento de los controles - tanto estatal como privado - de los espacios situados hacia el oeste; y por otro la desertificación de las áreas cercanas al río Chadileuvú a partir de la construcción del dique El Nihuil en la provincia de Mendoza.

En cuanto al primero de los factores, cabe aclarar que hacia la década de 1950 comenzaban a notarse los efectos de las políticas de los gobiernos territorianos de Evaristo Pérez Virasoro (1933-1939) y Miguel Duval (1939-1946), que buscaban un mayor control sobre áreas marginales del territorio. Esta política se reflejó en una vasta ampliación y mejora de las rutas existentes y - junto a ellas - la extensión de los alambrados por parte de propietarios privados. Para la población indígena, los cercamientos implicaban la limitación al acceso a recursos críticos tales como el agua, la leña y las pasturas para el ganado. Basilio Cabral, un habitante de Emilio Mitre, lo señala claramente:

«¿Qué no llovía? Algunas temporadas sí, años pasaron que no llovía. Pero se mantenía la gente ¡sabe por qué? Porque la gente iba, siempre buscó una sierra pa cortar leña. Porque yo cuando vine acá, nadie hacíamos palo de leña. Iba a cualquier campo, cortaba leña y no te decía $[n]$ nada. Pero después empezaron a corregirse las cosas. Este campo es mío y le voy a cerrar y bueno. Cerrado el campo igual le tenían que pedir permiso para sacar un poco de leña. Y hoy no porque hoy en realidad hay campos, están, todos los campos están cerrados y hay que pedir permiso para poder sacar leña y no te dan tampoco, te venden la leña. Y antes no se vendía, se daba la leña» ${ }^{25}$.

En cuanto al segundo, debemos tener presente que el oeste pampeano fue - y sigue siendo - una de las zonas más áridas del Territorio, con regímenes pluviales muy por debajo de los característicos en los departamentos orientales. Esta aridez era apenas atenuada por las zonas de influencia del río Atuel, su brazo occidental el Arroyo de la Barda y el río Chadileuvú (donde desem-

25 Testimonio de Basilio Cabral, tomado en Colonia Emilio Mitre, 2 de agosto de 1997, T104, lado A, Fondo Rankel, AHP. 
boca el Atuel) que integran la cuenca del Desaguadero. Ya durante la primera mitad del siglo fueron frecuentes las quejas de los inspectores de tierras acerca del uso que daban aguas arriba, en jurisdicción de la provincia de Mendoza, a los ríos Atuel y Chadileuvú, mermando - mediante embalses y desvíos para riego - los caudales de ambos. Sin embargo, la obra que determinó la profundización del proceso de desertización y el despoblamiento del área fue la construcción del dique El Nihuil, oficialmente inaugurado en 1948, pero que había comenzado a funcionar en los últimos meses del año 194726. Esta interrupción del curso del Atuel no sólo afectó sus tramos posteriores que recorrían el sector septentrional del departamento Chalileo, sino también el curso del Arroyo de la Barda que beneficiaba al sector oriental del departamento Chicalcó, y el mismo Río Salado, disminuido no sólo en su régimen sino en la calidad de sus aguas, ahora más salinizadas ${ }^{27}$.

Las migraciones fueron importantes por esos momentos: entre 1947 y 1960 todos los departamentos oesteños (a excepción de Puelén, el menos vinculado a la cuenca del Chadileuvú, y que además contaba con una población importante en la localidad de 25 de Mayo, atractora de los migrantes rurales y cuyas actividades económicas estaban más ligadas a la cuenca del río Colorado) experimentaron un brusca caída en sus niveles poblacionales, tal como se observa en el cuadro 1.

Los pobladores que lograron quedarse en la zona experimentaron una merma importante de los rebaños ${ }^{28}$ y un empeoramiento de las condiciones de vida. Entre este grupo de familias se encontraban los Cabral-Carripilón, que

26 Más detalles sobre las características de los diques sobre el río Atuel en Sarafian 2006.

27 Cabe aclarar que las dificultades en torno al control de este recurso continúan hasta la actualidad. Las provincias de Mendoza y La Pampa se encuentran enfrentadas judicialmente a través de las presentaciones que se hicieron desde mediados del siglo XX y hasta una última hecha por dos ONG a mediados del año 2007. Y es que el uso interprovincial no compartido ni coordinado causa graves consecuencias a los pobladores oesteños en general: cuando el caudal supera las cotas necesarias para riego se abren las compuertas mendocinas y los campos de abajo se inundan (como sucedió cuando las aguas llegaron hasta la localidad de Algarrobo del Aguila en el año 2007), en caso contrario, los cauces desaparecen, secando por completo los lechos y salinizándolos.

28 «I-Después el asunto con los ríos, se secaron los ríos. Bueno, en el año ’47 fue una sequía muy grande y la gente de aquí al sur se quedaron todos sin animales porque no tenían agua /.../ no, no había agua... Había remansos ¿vio?, remansos que se hacen por ahí pero el agua salada. E-¿Siempre fue salada así el agua? I-Se pone salada porque el agua está quieta. No como el agua que va corriendo porque el agua que va corriendo va limpiando todo. Y esos remansos no, porque el remanso se detiene el agua y agua detenida ese es malísima, cuando toma el animal se muere.» Testimonio de Basilio Cabral, cinta 104, Fondo Rankel, AHP. 
CUADRO 1. EVOLUCIÓN DE LA POBLACIÓN DE CUATRO DEPARTAMENTOS DEL OESTE DE LA PAMPA 1895-2000

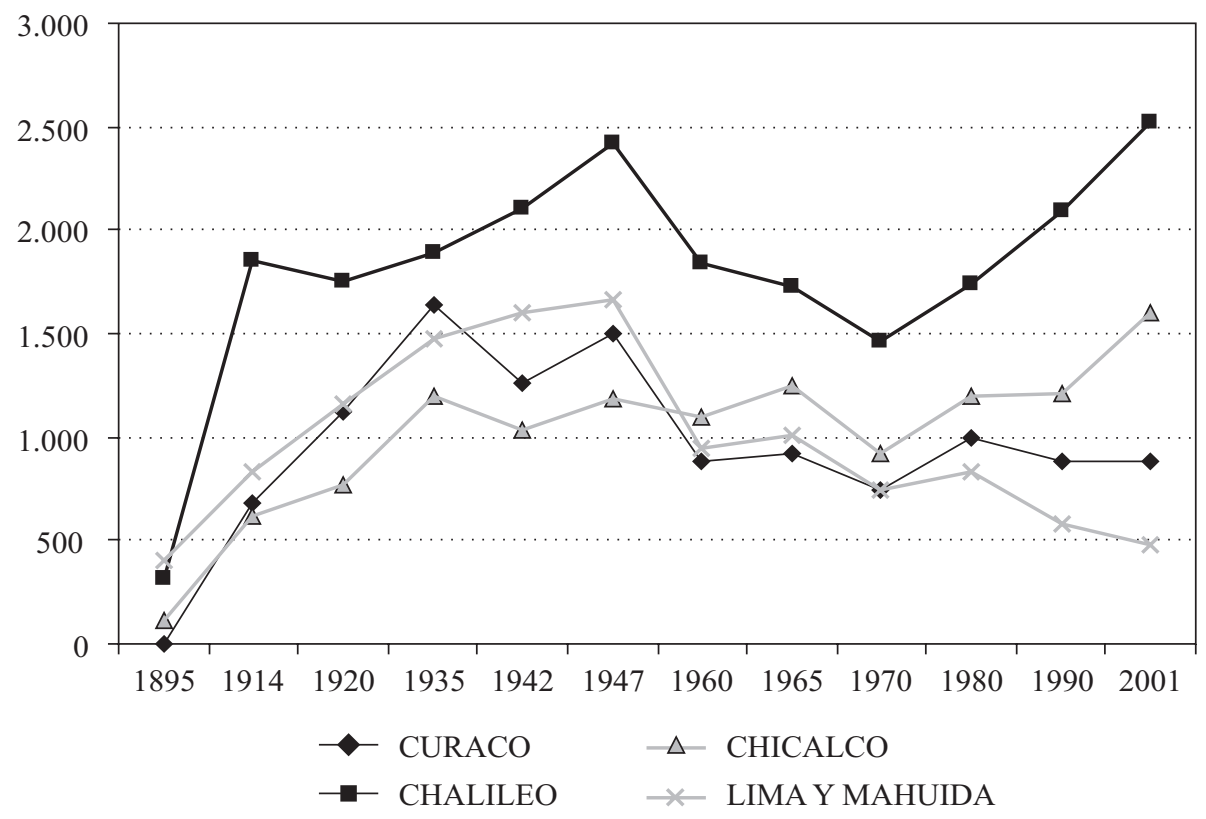

Fuente: Elaboración propia en base a censos nacionales, territorianos y provinciales entre 1895 y 2001.

fueron identificados en sucesivos estudios lingüísticos y antropológicos de las décadas de 1970 a 1990 como el núcleo del «Pueblito Cabral» ${ }^{29}$.

A la vez, las migraciones hacia medios urbanos se caracterizaron inicialmente por un desplazamiento a los poblados más cercanos a su lugar de residencia, ya sea porque quedaban familiares en los puestos (por lo general adultos mayores) a quienes brindar cuidados puntuales o asistencia, o bien porque sus marcos de referencia y mayor cantidad de paisanos ${ }^{30}$ estaban resi-

29 Nos referimos a los trabajos de Casamiquela \& Giordano 1975. Fernández Garay 1988. Poduje, Fernández Garay \& Crochetti 1993: 18-19. Medus y Poduje 1997. Poduje 2001. Fernández Garay 2002.

30 Entre los pobladores oesteños, el término paisano es marcadamente polisémico: a veces designa a personas residentes en áreas cercanas (coterráneos) o a parientes; en ocasiones, sostener que alguien es «paisano paisano» equivale a decir que es bien indio, en el sentido de que exhibe ciertos rasgos fisonómicos estereotipados, pero asimismo que posee ascendencia indí- 
diendo en esas localidades. Recién en una etapa posterior, progresivamente se encaminaron hacia pueblos y ciudades más alejadas. De esta manera, los destinos no fueron azarosos: estos ciclos de migración estuvieron asentados en las experiencias previas de circulación a partir de actividades laborales extraprediales, que de ser ocasionales comenzaron a convertirse en permanentes. Los patrones de movilidad territorial indican que las familias no migraron en forma aislada (como no se movilizaban tampoco en forma aislada en las actividades laborales, sino a partir de información que circulaba a través de vínculos de parentesco o en ámbitos de sociabilidad frecuentados por los oesteños). Los destinos habituales de los pobladores de la zona de Emilio Mitre fueron las localidades de Santa Isabel, Victorica y Telén en un primer momento, y más tarde Santa Rosa, capital del territorio y de la provincia. Por otro lado, los pobladores de la zona de Puelches migraron en su mayoría en un trayecto que se iniciaba en General Acha y podía continuar por Quehué y Toay hasta Santa Rosa, o bien desde aquélla directamente a esta última.

De esta manera, la mayoría de los nietos y bisnietos de Antonino Cabral (21 de los 25 que hemos hallado hasta ahora) nacieron y crecieron en Santa Isabel y Victorica (Departamentos Chalileo y Loventué respectivamente) y, en menor medida, en Santa Rosa. El resto de las personas de apellido Cabral — la mayoría de las cuales proviene del Departamento Chalileo, donde se encuentra Emilio Mitre - , según los procesamientos de datos generales, muestran tendencias similares: hemos registrado 1181 cambios de domicilios (que pueden corresponder en varias ocasiones a las mismas personas) y los hemos agrupado por décadas. A partir de la década de 1950 comienza a notarse una tendencia a la concentración de los Cabral en centros urbanos como Telén, Victorica y Santa Rosa que se profundizará en la década de 1970 y no cesará hasta nuestros días, tal como se observa en el cuadro 2 (ver página siguiente).

Por otro lado, los migrantes oesteños que arribaron entre las décadas de 1940 y 1960 se encontraron en una de las ciudades que registraba el mayor crecimiento en la provincia, pero con fuertes rasgos rurales: aunque estas características comenzarían a modificarse hacia fines de los ' 60 y principios de los '70, en los barrios marginales aún había terrenos amplios y era posible combinar los trabajos rurales en campos cercanos, con empleos urbanos más o menos estables, y obtener leña y pastaje para animales de trabajo en los alrededores.

gena comprobada. Por otra parte, hablar en paisano significa claramente hablar la lengua indígena (sea mapu-dungum, de los mapuche o che-dungum, de los rankülche). 


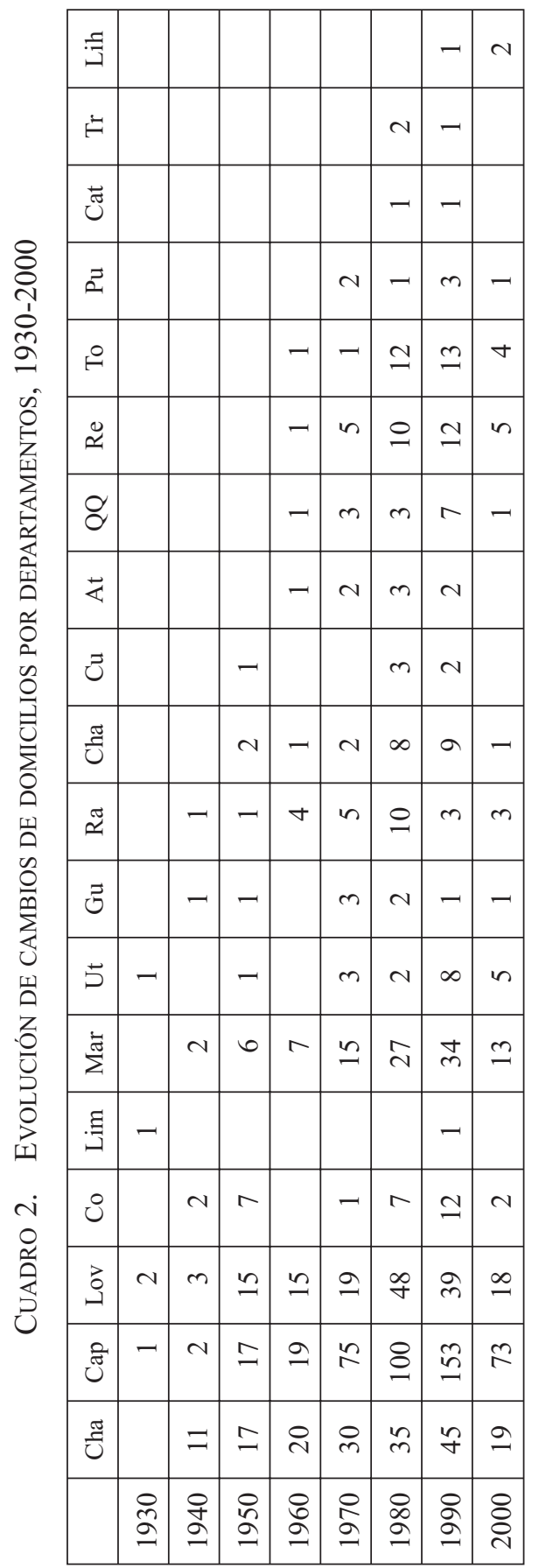

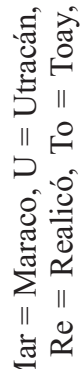

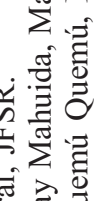

즁 త్

可॥

피 $₫$

$\stackrel{\Xi}{\Xi}$.

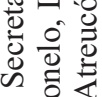

हैं $\|$

莺 0 安

疍造

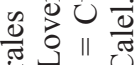

苟

엉 류

ปี तี

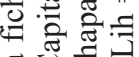

$\approx \circlearrowright \circlearrowright ⿻$

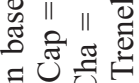

क

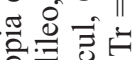

苞焉

:읏 $\|$

䒕

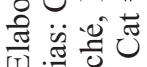

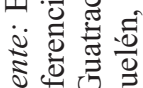

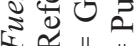

ت 
La instalación de los migrantes incluía varias etapas: aunque la llegada podía hacerse en forma aislada casi siempre se migraba hacia lugares donde hubiera parientes que facilitaran la ocupación de un terreno, colaboraran en la construcción de una vivienda precaria o bien brindaran hospedaje en la propia. La segunda etapa, de instalación definitiva, dependía de la combinación de una serie de factores entre los que se cuentan: el capital con que se arribaba, la posibilidad de conseguir vivienda y un empleo relativamente estable, la cercanía con paisanos que colaboraran en la resolución de problemas cotidianos (como cuidar los niños en horarios de trabajo), y la etapa del ciclo vital del núcleo familiar, entre otros.

Esta combinación de factores debía asegurar la cobertura de las necesidades básicas de alimentación y vivienda. La primera de ellas se lograba en base a la combinación de una serie de actividades como la caza de pequeños animales silvestres y la recolección en los montes cercanos a estos barrios, la cría de gallinas, el acceso a alimentos gratuitos (en muy escasa proporción) o la compra de comida barata a través de los ingresos obtenidos por trabajos asalariados. Estos trabajos eran normalmente los de hachero y jornalero en tareas rurales en el caso de los hombres (en los que colaboraban eventualmente las mujeres). En ámbitos urbanos las mujeres trabajaban como lavanderas, planchadoras, niñeras, y empleadas permanentes en casa de familia, mientras que los varones adultos lo hacían en el molino harinero cercano, en corralones, fletes de leña y/o materiales de construcción, albañilería y limpieza de terrenos. En todos los casos se trataba de tareas escasamente remuneradas que requerían baja calificación. La necesidad de que el trabajo infantil aportase a los ingresos del hogar conspiraba contra la permanencia de los niños en el sistema de educación formal, más allá de los primeros años de escolarización.

La segunda de estas necesidades básicas, la vivienda, era cubierta con todos los materiales a los que se pudiera acceder: bolsas de arpillera o nylon (de envase de frutas, verduras o cereales), maderas sacadas de cajones de frutas o de los comercios, chapas de descarte, ramas, palos (tomados de los árboles de los montes cercanos), cueros (de distinto tipo de animales) y todo aquel elemento que sirviera para cubrirse. A lo largo de la instalación, los pobladores procuraban construir con materiales como adobe y ladrillos, y cercar con alambre el lugar, aunque no fuera de propiedad privada ya que pese a la existencia de compra-ventas de terrenos, éstas no eran formalizadas por contrato y mucho menos mediante escrituras notariales. Estas condiciones de hacinamiento, excesivo frío o calor, escasa agua potable, y como hemos visto, una muy precaria alimentación y falta de acceso a recursos sanitarios, parecen haber estado en la base de la proliferación de enfermedades infecciosas que en 
ocasiones hacía que los niños fueran internados durante un tiempo (seguramente para recuperar su estado nutricional hasta niveles aceptables).

En tales contextos de inestabilidad laboral como una característica estructural, las prácticas reciprocitarias tendían a asegurar la provisión de los bienes necesarios para la subsistencia, y en este marco, se privilegiaba a los integrantes de la familia (nuclear o extensa) por sobre otros vínculos. Estos lazos reciprocitarios se reforzaban con el arribo periódico de trabajadores o parientes o conocidos de áreas rurales. En estas ocasiones, cuando se realizaban fiestas, todos los integrantes del barrio ${ }^{31}$ se reunían. Además, se aprovechaban los ámbitos de sociabilidad con personas de mejor posición económica (partidos de fútbol, charlas en cafés, trabajos en casas de familias acomodadas) como medio de obtener información sobre potenciales empleos para parientes y amigos, que solía circular por esos canales: ser paisano, entonces, también implicaba la posibilidad de asegurarse temporariamente la subsistencia.

\section{EPÍLOGO}

Los indios «... que existen en el territorio — informaba el gobernador del Territorio Juan Ayala al ministro del interior en su Memoria de 1888 - ascienden al número aproximado de ochocientos de todas las edades. Dependieron de la fuerza militar hasta el mes de junio del año ppdo. en que por el Ministerio de Guerra se decretó la suspensión del racionamiento con que se les atendía. La gobernación no teniendo recurso con que sostenerlos, se vio en el deber de adoptar medidas excepcionales en previsión de los perjuicios que podrían resultar para los habitantes del territorio /.../ Para el efecto, se dispuso su distribución por familias en los muchos establecimientos de campo que mejores ventajas les ofrecían, colocándose los demás, ya como postillones al servicio de las diversas mensajerias que cruzan el territorio ya en las diferentes industrias de los centros urbanos, con contratos equitativos, con lo que se logró asegurar la subsistencia de todos é inspirarles hábitos de trabajo. Al presente los indios no constituyen agrupación alguna, mezclados con los restantes de la población por toda la superficie del territorio» ${ }^{32}$.

31 Los principales barrios de Santa Rosa a los que arribó población indígena fueron Zona Norte, Villa Parque y El Salitral. Este último se constituyó en uno de los principales ámbitos de sociabilidad y circulación de información entre descendientes indígenas desde mediados del siglo XX.

32 Citado en Lluch 2005: 21. 
El discurso triunfalista de Ayala en cuanto a que los indios de su época no constituyeran agrupación alguna sería desmentido por los hechos pocos años más tarde. Parece claro, al menos, que los Cabral procuraron volver a reunirse en inmediaciones de Emilio Mitre y en todo el Departamento Chalileo a pesar de que habían sido llevados en forma forzada hacia General Acha. A la vez, sus patrones migratorios desde el oeste hacia las zonas urbanas a partir de la década de 1950 muestran regularidades en cuanto a los destinos: se concentrarán en Santa Isabel, Telén, Victorica y Santa Rosa, mientras que otros centros urbanos importantes como General Pico no resultarían de interés. Estas tendencias se verifican incluso hasta la actualidad. Según el padrón electoral del año 2003, hay en Santa Rosa 240 personas portadoras del apellido Cabral claramente concentradas en la zona norte de la ciudad, una de las más humildes y estigmatizadas $^{33}$. La mayoría de ellos (especialmente las generaciones nacidas en las décadas de 1960 a 1980) son oriundos de la misma capital, pero las segundas áreas en importancia de procedencia de los Cabral residentes en Santa Rosa son los Departamentos de Loventué y Chalileo ${ }^{34}$. Todo parece indicar que los Cabral, tanto mientras se encontraban radicados en áreas rurales, como cuando las abandonaron para migrar a las ciudades continuaron agrupándose en vecindad, ocupando determinados espacios urbanos.

Sin embargo, el discurso de Ayala contiene un dato innegable: la dispersión temprana como mano de obra asalariada de los indios amigos —entre los que se encontraban los integrantes del «Escuadrón Ranqueles». Esta fue la amarga y única recompensa que quiso dar la sociedad mayoritaria a cambio de las difíciles condiciones que - perdida su autonomía en momentos previos a las campañas militares de 1878-1885- debieron atravesar los indígenas. Como hemos visto a lo largo del caso que tomamos como ejemplo para este estudio, Ramón Cabral y los suyos enfrentaron varias situaciones adversas para sobrevivir como grupo: primero, las incursiones de los grupos militares en la frontera de Córdoba, luego el hambre y la viruela, más tarde la escasez de recursos y poca productividad de las tierras que les habían otorgado, posteriormente el control y las sequías sumado al corte de los ríos, y por fin las difíciles condiciones de vida en las ciudades. Estas condiciones, sin embargo, no

33 De esta población (un universo de 230 que declararon ocupación al momento de enrolarse o hacer cambios de domicilio), la mayoría de las mujeres declaran ser amas de casa y empleadas, aunque en algunos casos esta declaración podría encubrir el trabajo en servicio doméstico en forma permanente. Entre los hombres por otra parte, es muy clara la tendencia al trabajo como jornaleros y albañiles.

34 Según la información que puede encontrarse en sus fichas individuales en Secretaría Electoral, JFSR. 
eran muy distintas de aquéllas que debieron atravesar $-\mathrm{y}$ ante las cuales elaboraron diferentes estrategias - , el resto de las poblaciones indígenas subalternizadas desde fines del siglo XIX en Argentina.

\section{BIBLIOGRAFÍA}

Argeri, María E., De guerreros a delincuentes. La desarticulación de las jefaturas indígenas y el poder judicial: Norpatagonia, 1880-1930, Madrid, Consejo Superior de Investigaciones Científicas, 2005.

Bechis, Martha, «Los lideratos políticos en el área araucano-pampeana en el siglo XIX: ¿poder o autoridad?», María de Hoyos (coord.), Etnohistoria, Número especial de la revista Noticias de Arqueología y Antropología (Naya), editado en disco compacto, 1999.

Beverley, John, «La persistencia del subalterno», Nómadas, n. ${ }^{\circ} 17$ (Bogotá, octubre de 2002): 48-56.

Boccara, Guillaume e Ingrid Seguel-Boccara, «Políticas indígenas en Chile (Siglos XIX y XX). De la asimilación al pluralismo (El caso mapuche)», Revista de Indias, vol. LIX, n. 217 (Madrid, 1999): 741-774.

Briones, Claudia, "Construcciones de aboriginalidad en Argentina», Société suisse des Américanistes/Schweizerische Amerikanisten-Gesellschaft, Bulletin 68 (Ginebra, 2004): 73-90.

Briones, Claudia y Walter Delrio, «Patria sí, colonias también. Estrategias diferenciadas de radicación de indígenas en Pampa y Patagonia», Ana Teruel, Mónica Lacarrieu y Omar Jerez (comps.), Fronteras, ciudades y estados, Córdoba, Alción Editora, 2002: 45-78.

Casamiquela, Rodolfo y Amanda Giordano, Informe Colonia General Emilio Mitre, Santa Rosa (mimeo, depositado en Archivo Histórico Provincial), 1975.

Chakrabarty, Dipesh, «Una pequeña historia de los Estudios Subalternos», versión online disponible en Laboratorio de Desclasificación Comparada: http://www.desclasificacion.org/doc_comp.html, 2000.

De Jong, Ingrid, «Armado y desarmado de una Confederación: el liderazgo de Calfucurá en el periodo de la organización nacional (1852-1873)», ponencia presentada al simposio El liderazgo indígena en los espacios fronterizos americanos (siglos XVIII-XIX), Buenos Aires, 2 y 3 de agosto de 2007.

Delrio, Walter, Memorias de Expropiación. Sometimiento e incorporación indígena en la Patagonia, 1872-1943, Bernal, Universidad Nacional de Quilmes, 2005.

Delrio, Walter, «Indios amigos, salvajes o argentinos. Procesos de construcción de categorías sociales en la incorporación de los pueblos originarios al estado-nación 
(1870-1885), en Lidia Nacuzzi (comp.), Funcionarios, diplomáticos, guerreros. Miradas hacia el otro en las fronteras de Pampa y Patagonia (siglos XVIII y XIX), Buenos Aires, Sociedad Argentina de Antropología, 2002: 203-245.

Depetris, José Carlos, Gente de la Tierra. Los que sobrevivieron a la conquista, con nombre y apellido. Censo de 1895. Pampa Central, Santa Rosa, Ediciones De la Travesía, 2003.

Depetris, José Carlos y Walter Cazenave, Crónicas Ranquelinas, Santa Rosa, Departamento de Investigaciones Culturales, 1998.

Depetris, José Carlos y Pedro Vigne, Los Rostros de la Tierra. Iconografía indígena de La Pampa. 1870-1950, Santa Rosa, Amerindia-Universidad Nacional de Quilmes, 2000.

Fernández Garay, Ana, Relevamiento lingüistico de hablantes mapuches en la Provincia de La Pampa, Santa Rosa, Departamento de Investigaciones Culturales (Dirección General de Cultura, Gobierno de la Provincia de La Pampa), 1988.

Fernández Garay, Ana, Testimonios de los últimos ranqueles, Buenos Aires, Instituto de Lingüística, Facultad de Filosofía y Letras, UBA, 2002.

Hernández, Isabel, La identidad enmascarada. Los Mapuche de Los Toldos, Buenos Aires, EUDEBA, 1993.

Gramsci, Antonio, «Apuntes sobre la historia de las clases subalternas. Criterios de método», en A. Gramsci, Escritos políticos (1917-1983), México, Siglo XXI, 1998 (6ta.edición).

Grupo Latinoamericano de Estudios Subalternos, «Manifiesto Inaugural», Santiago Castro-Gómez y Eduardo Mendieta, Teorías sin disciplina (latinoamericanismo, poscolonialidad y globalización en debate), México, Miguel Ángel Porrúa, 1998.

Guha, Ranajit, Las voces de la historia y otros estudios subalternos, Barcelona, Crítica, 2002.

Hux, Meinrado, Caciques Pampa-Ranqueles, Buenos Aires, Marymar, 1991.

Lagos, Marcelo, «Problemática del aborigen chaqueño. El discurso de la "integración”, 1870-1920», Ana Teruel y Omar Jerez (eds.), Pasado y presente de un mundo postergado. Estudios de antropología, historia y arqueología del Chaco y Pedemonte Surandino, Jujuy, Universidad Nacional de Jujuy, 1998: 57-101.

Lenton, Diana, «Los Indígenas y el Congreso de la nación Argentina: 1880-1976», Revista de Antropología y Arqueología, año 2, n. ${ }^{\circ}$ 14, junio 1997, disponible en www.naya.org.ar/articulos/identi09.htm

Lluch, Andrea, «Un largo proceso de exclusión. La política oficial y el destino final de los indígenas ranquelinos en La Pampa (Argentina) a través de un estudio de caso», Quinto Sol. Revista de Historia Regional, año 6, n. 6 (Santa Rosa, 2002): 43-68. 
Lluch, Andrea (ed.), Memorias de Gobernadores del Territorio Nacional de La Pampa, vol. 1, Santa Rosa, EdUNLPam, 2005.

Mallon, Florencia E., «Promesa y dilema de los estudios subalternos: perspectivas a partir de la historia latinoamericana», Boletín del Instituto de Historia Argentina y Americana "Dr. Emilio Ravignani", 3. ${ }^{\text {ra }}$ serie, N. ${ }^{\circ} 12$ (Buenos Aires, 1995): 87-116.

Mandrini, Raúl J., Los araucanos de las pampas en el siglo XIX (selección y prólogo), Buenos Aires, Centro Editor de América Latina, 1984.

Mansilla, Lucio V., Una excursión a los indios ranqueles, Buenos Aires, Centro Editor de América Latina, tomos 1 y 2, 1980.

Mases, Enrique Hugo, Estado y cuestión indígena. El destino final de los indios sometidos en el sur del territorio (1878-1910), Buenos Aires, Prometeo Libros/Entrepasados, 2002.

Medus, Norma y María Inés Poduje, Las manos de la memoria. Artesanos tradicionales de La Pampa, Santa Rosa, Departamento de Investigaciones Culturales, Subsecretaría de Cultura de la Provincia de La Pampa, 1997.

Mezzadra, Sandro (comp.), Estudios poscoloniales. Ensayos fundamentales, Madrid, Traficantes de sueños, 2008.

Moraña, Mabel, «El boom del subalterno», en Santiago Castro-Gómez y Eduardo Mendieta, Teorías sin disciplina (latinoamericanismo, poscolonialidad y globalización en debate), México, Miguel Ángel Porrúa, 1998.

Moraña, Mabel, Enrique Dussel y Carlos Jáuregui, Coloniality at large: Latin America and the postcolonial debate, Durham, Duke University Press, 2008.

Moroni, Marisa, «Fortalecer el Estado y unificar el territorio. Organización y gobierno del Territorio Nacional de la Pampa, Argentina a fines del siglo XIX», Boletín Americanista, año LVII, n. 57 (Barcelona, 2007): 199-218.

Nicoletti, María Andrea, Indígenas y misioneros en la Patagonia: huellas de los salesianos en la cultura y la religiosidad de los pueblos originarios, Buenos Aires, Continente, 2008.

Otero, Hernán, «Estadística censal y construcción de la nación. El caso argentino, 1869-1914», Boletín del Instituto de Historia Argentina y Americana «Dr. Emilio Ravignani», 3. ${ }^{\text {ra }}$ serie, n. ${ }^{\text {os }}$ 16-17 (Buenos Aires, 1998): 123-149.

Pérez Zavala, Graciana, «La política interétnica de los ranqueles durante la segunda mitad del siglo XIX», Quinto Sol. Revista de Historia Regional, n. ${ }^{\circ} 11$ (Santa Rosa, 2007): 61-89.

Pinto Rodríguez, Jorge, «Bárbaros, demonios y bárbaros de nuevo: estereotipos del mapuche en Chile, 1550-1900», Susana Bandieri (coord.) Cruzando la Cordillera... La frontera argentino-chilena como espacio social, Neuquén, Centro de Estudios de Historia Regional-Universidad Nacional del Comahue, 2001: 119-140. 
Poduje, María Inés, Presencia ranquelina, Santa Rosa, Departamento de Investigaciones Culturales, Subsecretaría de Cultura de la Provincia de La Pampa, 2001.

Poduje, María Inés, Ana Fernández Garay y Silvia Crochetti, Narrativa ranquel. Los cuentos del zorro, Buenos Aires, Ministerio de Cultura y Educación de la Nación-Ministerio de Cultura y Educación de la Provincia de La Pampa, 1993.

Prins, Harald, «Paisanos en La Pampa. Supervivencia indígena en el interior de Argentina» (mimeo, depositado en Archivo Histórico Provincial «Prof. Fernando Araoz», Santa Rosa, La Pampa), 1987.

Quijada, Mónica, «La question indienne», Cahiers Internationaux de Sociologie, vol. CV (Paris, 1998): 305-323.

Quijada, Mónica, «“"Hijos de los barcos” o diversidad invisibilizada? La articulación de la población indígena en la construcción nacional argentina (siglo XIX)», Historia Mexicana, año/vol. LIII, n. ${ }^{o} 2$ (México D.F., 2003): 469-510.

Rodríguez, Ileana (ed.), Latin American subaltern studies reader, Durham, Duke University Press, 2001.

Salomón Tarquini, Claudia, «Ranqueles, Franciscanos, Militares, Funcionarios: De la autonomía a la incorporación subordinada de grupos indígenas al Territorio Nacional de la Pampa Central (1850-1910)», ponencia presentada en las X Jornadas Interescuelas/Departamentos de Historia, Rosario, 20 a 23 de septiembre de 2005.

Sánchez, Fernando Miguel, «Construcción de alteridad e incorporación subordinada de los indígenas en el Territorio Nacional del Neuquén», ponencia presentada a las IX Jornadas Interescuelas/Departamentos de Historia, Córdoba, 24, 25 y 26 de septiembre de 2003 (editado en disco compacto).

Sarafian, Paula, «Cuenca del Atuel», 2006, disponible en: http://www.hidricosargentina.gov.ar/59.pdf (consultado mayo 2008).

Tamagnini, Marcela y Graciana Pérez Zavala, «Políticas colonizadoras en la frontera del río Quinto: las reducciones franciscanas (1854-1880)», ponencia presentada al VI Congreso Internacional de Etnohistoria, Buenos Aires, 22 al 25 de noviembre de 2005.

Tamagnini, Marcela y Graciana Pérez Zavala, «Caminos inversos: indios reducidos y refugiados políticos en la Frontera Sur», ponencia presentada en las Primeras Jornadas de Historia Social, La Falda, Córdoba, 30 y 31 de mayo y 1 de junio de 2007.

Tamagnini, Marcela y Graciana Pérez Zavala, «El debilitamiento de los ranqueles: el tratado de paz de 1872 y los conflictos intraétnicos», Lidia Nacuzzi (comp.), Funcionarios, diplomáticos, guerreros. Miradas hacia el otro en las fronteras de Pampa y Patagonia (siglos XVIII y XIX), Buenos Aires, Sociedad Argentina de Antropología, 2002: 119-157. 
Villar, Daniel, Ocupación y control del espacio por las sociedades indígenas de la frontera sur de Argentina (siglo XIX). Un aporte al conocimiento etnohistórico de la Región Pampeana, Bahía Blanca, Departamento de Humanidades, UNSur, 1993.

Villar, Daniel y J. F. Jiménez, «Un Argel disimulado. Aucan y poder entre los corsarios de Mamil Mapu (segunda mitad del siglo XVIII)», en revista Nuevo Mundo Mundos Nuevos, n. ${ }^{\circ} 3,2003$, disponible en: http://nuevomundo.revues.org/document656.html

Fecha de recepción: 28 de septiembre de 2009

Fecha de aceptación: 28 de septiembre de 2010

\section{Subalternation processes of the indigenous population in Argentina: Ranqueles in The Pampa, 1870-1970}

As a result of the military campaigns of 1878-1885, known in Argentina as "The Conquest of the Desert", the indigenous populations tried different strategies to face the adverse conditions and the policies that sought their subalternization and invisibilization. This work explores the peculiarities of the process carried out by the ranquel ethnic group, in the Pampa (initially a National Territory that later became a province in 1952) from the last years of their autonomy up until the 1970s. The study is based on the cross-checking of different sources that, reducing the range of the analysis uses the trajectory of the groups that were tied to the cacique Ramon Cabral, El Platero, as an example of such processes.

KEY WORDS: Pampa; indigenous populations; subaltern studies; resistance strategies. 